KINETIK, Vol. 2, No. 1, Februari 2016, Hal. 63-70

ISSN : 2503-2259,

E-ISSN : 2503-2267

\title{
Pemetaan Subdomain Pada Cloud Server Universitas Semarang Menggunakan Metode Port Forwarding dan Reverse Proxy
}

\author{
Mohammad Sani Suprayogi ${ }^{\star 1}$, Prind Triajeng Pungkasanti ${ }^{2}$ \\ Universitas Semarang \\ yogie@usm.ac.id*
}

\begin{abstract}
Abstrak
Manajemen Jaringan adalah bagian dari ilmu komputer yang berkaitan dengan pengaturan sumberdaya, optimasi, dan keamanan jaringan komputer. Port forwarding dan reverse proxy merupakan salah satu cara untuk pemetaan alamat dalam jaringan komputer. Penelitian mengenai cloud computing telah mulai banyak dilakukan, namun pembahasan mengenai manajemen jaringan masih sering menggunakan metode bridge, yang membutuhkan banyak ip public. Universitas Semarang telah mengimplementasikan cloud computing namun memiliki keterbatasan ip public, sehingga membatasi jumlah server dalam jaringan cloud Universitas Semarang. Hampir sebagian besar universitas dan institusi lain memiliki masalah yang sama (keterbatasan jumlah ip public), maka penelitian ini bertujuan untuk menghasilkan suatu konfigurasi pada server cloud dengan tujuan untuk mengoptimalkan ip private dalam jaringan, kemudian memetakan subdomain dan ip private pada setiap server supaya dapat diakses oleh pengunjung. Hasilnya Universitas Semarang hanya membutuhkan satu ip public yang berfungsi sebagai gateway terhadap server-server yang berjalan di jaringan cloud. Selain itu teknik ini dapat menjadi pengayaan dalam mata kuliah Jaringan Komputer.
\end{abstract}

Kata kunci: Cloud computing, Network management, Private cloud

\begin{abstract}
Network Management is a part of computer science-related resource settings, optimization, and security of computer networks. Port forwarding and reverse proxy is one way to address mapping in a computer network. There has been many research about cloud computing, but most of them still use bridge method that requires a lot of public ip. University of Semarang has implemented cloud computing but has limited public ip, which limits the number of servers in the network cloud. Most of the universities and other institutions have the same problem (a limited number of public ip), this study aims to generate a configuration on the server cloud by optimizing the IP private network, and then map the subdomain and ip private on any server to make it easier to access. Result shows that University of Semarang requires only one public ip which serves as a gateway to servers running on the network cloud. In addition, this technique also can enrich the course of Computer Networks.
\end{abstract}

Keywords: Cloud computing, Network management, Private cloud

\section{Pendahuluan}

Institusi pendidikan telah mulai memanfaatkan Teknologi Informasi dalam pelaksanaan Tridharma Perguruan Tinggi. Namun pada praktiknya masih menemui beberapa hambatan, seperti infrastruktur kurang memadai, layanan yang tidak terintegrasi, kurangnya kompetensi dalam memanajemen, dan perlunya standardisasi dalam strategi implementasi IT [1].

Cloud computing, sebagaimana yang disebutkan oleh Zhang, et al. [2] pengembangan grid computing yang memaksimalkan penggunaan sejumlah perangkat IT sekaligus akan menurunkan konsumsi energi. Hal inilah yang menarik minat penulis pada penelitian sebelumnya, yaitu membahas strategi implementasi cloud computing di Institusi Pendidikan, dengan studi kasus Universitas Semarang (USM) [3].

Hasil dari penelitian tersebut, Universitas Semarang (USM) telah mengimplementasikan cloud computing pada beberapa layanan untuk menggantikan server fisik menggunakan 
strategi ROCCA (roadmap for cloud computing adoption). Setiap virtual server yang berjalan telah terkoneksi secara bridge ke cloud server dan diberikan identitas berupa subdomain usm.ac.id kemudian dialamatkan ke IP Public supaya dapat diakses dari Internet.

Di Universitas Semarang saat ini baru terdapat 5 virtual server menggunakan 5 IP Public karena keterbatasan jumlah IP Public yang dimiliki. USM akan mengalami masalah jika ada penambahan virtual server yang membutuhkan IP Public karena IP Public yang lain telah dialokasikan ke layanan yang telah berjalan sebelumnya. Hal ini yang membuat penggunaan cloud computing di Universitas Semarang dirasa kurang maksimal, sesuai yang disebut oleh Cenka, et al. [1], yakni hambatan infrastruktur.

Dalam mata kuliah Jaringan Komputer terdapat bab routing yang bertugas memetakan alamat dalam sebuah jaringan. Saat ini, setiap server yang berjalan di cloud server masih diberikan sebuah IP Public, nantinya setiap server cukup diberi IP Private kemudian dipetakan alamatnya dengan memberikan alamat subdomain. Sehingga nantinya infrastruktur cloud cukup membutuhkan satu IP Public yang akan digunakan secara bersama oleh semua server. Hal ini nantinya akan menghemat penggunaan IP Public di USM dan tentunya dapat menjadi pengayaan materi mata kuliah Jaringan Komputer.

\section{Tinjauan Pustaka}

Penelitian mengenai cloud computing sektor pendidikan (cloud education) merupakan topik yang menarik, hal ini dikarenakan sektor pendidikan memiliki karakteristik yang berbeda dibandingkan dengan sektor industri ataupun pemerintahan, antara lain pada IT Governance dan IT Infrastructure [1]. Penelitian mengenai strategi implementasi cloud computing di sektor pendidikan telah peneliti lakukan [3], setelah sebelumnya dilakukan pada sektor UMKM [4, 5], dan pemerintah daerah [6]. Beberapa penelitian tersebut berhasil mengimplementasikan cloud computing dengan hasil nyata berupa pengurangan jumlah server fisik yang dapat menghemat dari sisi penggunaan energi dan biaya. Namun dari semua penelitian tersebut, masih membahas sebatas strategi adopsi cloud computing, adapun pembahasan yang bersifat teknis, terutama pada penggunaan ip Public masih belum tersentuh, sehingga meskipun jumlah server fisik telah berkurang, namun jumlah penggunaan IP Public masih tetap jumlahnya.

Alamat IP (IP Address) merupakan deretan angka yang diberikan ke setiap perangkat serta terhubung pada jaringan komputer agar dapat berkomunikasi menggunakan Internet Protocol [7]. Pengguna Internet di Indonesia yang mencapai 73 juta di tahun 2015 [8] telah meningkatkan permintaan IP Address supaya dapat terhubung ke Internet, padahal jumlah slot IP Address versi 4 (IPv4) saat ini telah menipis meskipun telah dikembangkan IP Address versi 6 (IPv6). Namun bagi institusi pendidikan, proses migrasi dari IPv4 ke IPv6 cukup menjadi kendala karena masalah kompetensi sumber daya seperti yang telah disebutkan pada penelitian Cenka, et al. [1].

Solusi yang bisa dilakukan adalah dengan memanfaatkan private network $[9,10]$ sehingga cukup membutuhkan satu IP Public saja kemudian melakukan pemetaan menggunakan port forwarding dengan IPTables dan reverse proxy. Hingga saat ini belum banyak penelitian mengenai reverse proxy yang telah dilakukan, Setijadi, et al. [11] baru membahas penggunaan reverse proxy yang digabungkan dengan load balancer pada LMS, sebelumnya Chu-Hsing, et al. [12] telah memanfaatkan reverse proxy sebagai pendeteksi serangan web flooding. Penelitian ini akan berfokus dalam penggunaan reverse proxy dan port forwarding pada infrastruktur cloud server berfungsi untuk memetakan alamat berdasarkan subdomain pada private network Universitas Semarang (USM).

\section{Metode Penelitian \\ 3.1 Metode Pengumpulan Data}

Sebelum melakukan penelitian, pengumpulan data merupakan tahapan penting supaya dapat mengetahui permasalahan secara lebih mendalam, adapun metodenya akan dilakukan sebagai berikut:

1. Metode Studi Pustaka

Melakukan studi pustaka dengan studi literatur atau membaca buku-buku, Internet, dan catatan-catatan yang menunjang penelitian pemetaan subdomain cloud server Universitas Semarang menggunakan port forwarding dan reverse proxy. 
2. Metode Observasi

Observasi adalah teknik di mana peneliti mengamati objek atau hal-hal yang diperlukan dalam pemetaan. Pada bagian ini peneliti mengunjungi lokasi ruang server Universitas Semarang yang berada di Gedung E.

\subsection{Metode Pengembangan Sistem}

Pengembangan jaringan komputer merupakan kegiatan yang terus berkesinambungan sehingga tahap perencanaan merupakan hal terpenting. Model PPDIOO (prepare, plan, design, implement, operate, and optimize) [13] dinilai metode yang tepat untuk memulai pengembangan jaringan komputer, adapun tahapannya sebagai berikut:

1. Prepare

Pada tahapan prepare, peneliti menentukan strategi dan model bisnis jaringan cloud pada Universitas Semarang, sehingga dapat menentukan rancangan pada tahap selanjutnya.

2. Plan

Peneliti melakukan perencanaan kebutuhan jaringan cloud USM, menganalisis permasalahan, dan menentukan waktu pelaksanaan.

3. Design

Pada tahap ini, peneliti mulai membuat desain network secara mendetail yang akan diimplementasikan pada jaringan cloud USM.

4. Implement

Tahap ini, peneliti melakukan implementasi terhadap rencana dan desain yang telah dilakukan sebelumnya.

5. Operate

Tahap operate merupakan tahapan yang cukup menentukan, karena pada tahap ini jaringan cloud harus sudah berjalan kemudian melakukan monitoring terhadap jaringan tersebut.

6. Optimize

Peneliti melakukan optimasi dan memperbaiki apabila ada masalah. Selain itu juga sembari meningkatkan performa dan menjaga stabilitas jaringan.

\subsection{Lokasi Penelitian}

Penelitian dilakukan di Universitas Semarang dengan sasaran pengguna hasil penelitian ini adalah mahasiswa Teknik Informatika dengan mata kuliah Jaringan Komputer.

\section{Analisis dan Perancangan}

\subsection{Analisis Cloud computing}

Infrastruktur TIK (jaringan, server, data center) milik institusi pendidikan biasanya terpusat di kompleks kampus tersebut. Indonesia rawan akan bencana sehingga ada baiknya data dan aplikasi yang ada dibuatkan cadangannya. Keuntungan cloud computing bahwa lokasi penyimpanan data yang bisa dimana saja dapat dimanfaatkan bila terjadi force majeur di lokasi pemilik data berada. Walaupun mengakibatkan kerusakan infrastruktur yang parah, data yang terletak di cloud tetap aman. Selain itu cloud computing memungkinkan pemulihan layanan dengan cepat tanpa harus menunggu perbaikan infrastruktur selesai [14].

Strategi pemanfaatan cloud computing yang disusun oleh perusahaan Intel, ditekankan pembuatan internal cloud sebagai langkah awal, yaitu dengan mengubah infrastruktur yang telah ada menjadi cloud dan mengubah semua layanan yang ada menjadi layanan berbasis cloud. Setelah transisi menjadi internal cloud selesai, maka mulai direncanakan migrasi layanan, baik yang baru maupun yang ada ke external cloud [15]. Melihat bahwa salah satu dasar dari cloud computing adalah virtualisasi, maka alternatif pemanfaatan yang dapat diambil oleh institusi pendidikan adalah membuat private cloud di lokasi milik sendiri dan menjalankan aplikasi dalam server virtual.

\subsection{Tahap Prepare}

Tahap ini merupakan persiapan sebelum melakukan perancangan terhadap konfigurasi cloud yang akan dilakukan, yakni dengan mengumpulkan data-data relevan. Data yang dikumpulkan untuk tahap awal ini berasal dari proses wawancara, melibatkan beberapa pihak, antara lain Kepala Puskom USM sebagai penanggung jawab jaringan dan infrastruktur komputer dan Koordinator Unit PSIT sebagai pihak developer aplikasi di Universitas Semarang. 
Wawancara dilakukan mengacu pada artikel Canonical [16] yang memfokuskan pada hal budget atau anggaran dana, sumber daya manusia, waktu untuk deployment project, kebutuhan dan peningkatan teknologi IT, serta yang terakhir masalah keamanan dan privasi data.

Kesimpulan hasil wawancara, yaitu pihak Puskom USM bersedia untuk dilaksanakan optimasi cloud computing pada Universitas Semarang dan berkomitmen memberikan dukungan terkait masalah administrasi dan anggaran, walaupun jumlahnya terbatas dan harus diajukan di awal pelaksanaan adopsi. PSIT menegaskan kebutuhan server sudah dalam kondisi mendesak, dan diharapkan dapat menjadi solusi ketersediaan server dan dapat dilakukan secara mudah dan cepat.

Setelah proses pengumpulan data primer selesai dilakukan, maka langkah selanjutnya adalah mengumpulkan data sekunder berupa artikel mengenai implementasi cloud computing. Data sekunder digunakan untuk mempelajari konsep dan mengetahui berbagai jenis dari implementasi cloud computing. Sumber data yang lain berasal dari observasi terhadap sistem yang telah tersedia di Universitas Semarang, hal ini untuk mengetahui model implementasi dan layanan apa yang cocok untuk diterapkan.

\subsection{Tahap Planning}

Tahap ini merupakan perancangan menggunakan data-data yang didapatkan pada saat melakukan tahap planning. Perancangan yang dilakukan, yakni menentukan topologi jaringan yang menghubungkan antara jaringan cloud dengan jaringan Internet, supaya nantinya virtual server yang berada di jaringan cloud dapat diakses melalui Internet.

Berdasarkan hasil observasi, saat ini jaringan cloud yang telah berjalan masih menggunakan metode bridge untuk menghubungkan antar virtual server, sehingga setiap virtual server yang berjalan membutuhkan IP Public supaya dapat diakses dari Internet. Hal ini menjadi masalah pada saat pengimplementasian cloud computing di Universitas Semarang, karena jumlah IP Public yang dimiliki terbatas dan merupakan jatah dari ISP yang dilanggan.

Maka dari itu, peneliti memberikan solusi dengan menggunakan metode Port Forwading dan Reverse Proxy. Port forwarding adalah fitur yang dimiliki oleh semua perangkat router, kemudian Reverse Proxy adalah metode pengalamatan menggunakan web server yang berguna untuk memetakan alamat sub domain yang dipanggil oleh pengguna, kemudian nantinya permintaan tersebut akan diteruskan ke virtual server yang telah terdaftar. Adapun topologi yang akan dibangun dapat dilihat pada Gambar 1.

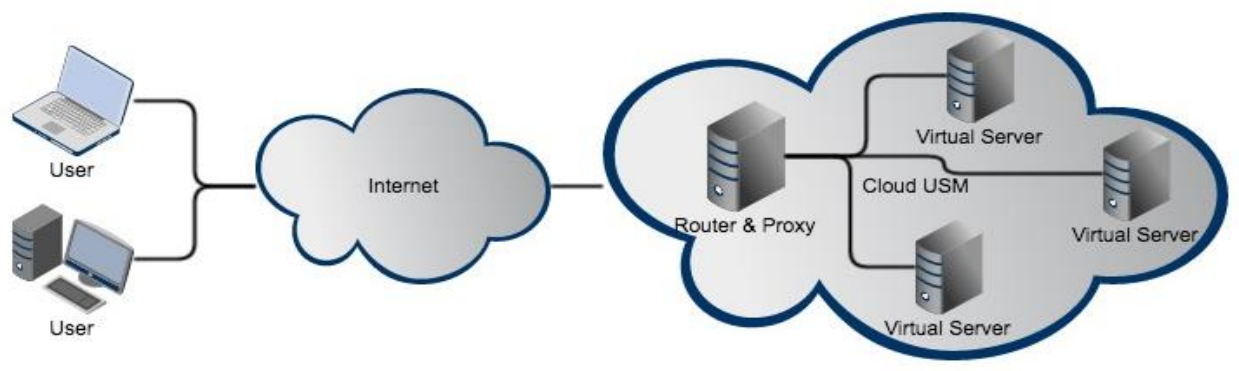

Gambar 1. Rencana Topologi Jaringan Cloud Universitas Semarang

\section{Implementasi}

\subsection{Tahap Design}

Pada Implementasi dilakukan adalah dengan membuat desain detail berdasarkan topologi jaringan pada Gambar 1. Seperti yang sudah disebutkan sebelumnya, saat ini Universitas Semarang memiliki 5 virtual server seperti yang terlihat pada Tabel 1. Kelima virtual server tersebut menjalankan layanan yang dapat diakses melalui Internet, sehingga memerlukan IP Public dan telah diberikan alamat subdomain untuk mengakses layanannya. Saat ini jumlah IP Public yang dimiliki USM telah terbatas, padahal dalam waktu dekat USM akan meluncurkan beberapa layanan baru, sehingga perlu ada modifikasi konfigurasi penggunaan IP Public. 
Tabel 1. Daftar Virtual Server Universitas Semarang

\begin{tabular}{ll}
\hline \multicolumn{1}{c}{ ID Server } & \multicolumn{1}{c}{ Layanan } \\
\hline 101 & Sijalu - Sistem Informasi Jurnal IImiah USM \\
\hline 102 & LAB FTIK \\
\hline 103 & TA-FTIK \\
\hline 104 & KP-FTIK \\
\hline 105 & BPM - Badan Penjaminan Mutu USM \\
\hline
\end{tabular}

Seperti yang telah dibahas juga pada tahapan planning, bahwa nantinya seluruh virtual server akan menggunakan IP Private. Maka peneliti membuatkan daftar IP Private dan URL untuk masing-masing virtual server seperti pada Tabel 2. Virtual server yang menggunakan IP Private tersebut dapat diakses melalui jaringan Intranet USM, namun perlu dikonfigurasi supaya dapat diakses melalui Internet. Maka dari itu peneliti menggunakan metode Reverse Proxy.

Tabel 2. Daftar IP Private Virtual Server Universitas Semarang

\begin{tabular}{ccc}
\hline ID Server & \multicolumn{1}{c}{ URL } & IP Address \\
\hline 101 & http://journal.usm.ac.id & 192.168 .135 .101 \\
\hline 102 & http://lab.ftik.usm.ac.id & 192.168 .135 .102 \\
\hline 103 & http://ta.ftik.usm.ac.id & 192.168 .135 .103 \\
\hline 104 & http://kp.ftik.usm.ac.id & 192.168 .135 .104 \\
\hline 105 & http://bpm.usm.ac.id & 192.168 .135 .105 \\
\hline
\end{tabular}

Metode Reverse Proxy memungkinkan setiap virtual server yang memiliki ip private dapat diakses melalui Internet menggunakan alamat sub domain yang telah diberikan. Adapun implementasi metode reverse proxy akan menggunakan web server Nginx sebagai gateway yang akan meneruskan permintaan dari pengunjung kepada virtual server yang tersedia. Kemudian untuk keperluan akses lain seperti layanan SSH terhadap masing-masing virtual server, peneliti menggunakan layanan port forwarding dengan IPTables yang akan membuka akses setiap virtual server dengan port spesifik.

\subsection{Tahap Implementasi}

Sesuai dengan topologi pada Gambar 1 maka peneliti membuatkan satu virtual server yang diberi IP Private 192.168.135.100 dan diinstall dengan sistem operasi Ubuntu 14.04 LTS kemudian menginstall web server Nginx yang akan dijadikan sebagai Reverse Proxy. Adapun konfigurasi Nginx adalah dengan membuat file konfigurasi pada folder/etc/nginx/conf.d.

Setiap virtual server yang akan diarahkan ke subdomain yang telah ditentukan akan dibuatkan file tersendiri, sehingga nantinya pada folder Nginx akan terdapat 5 file dengan format subdomain.conf. Sebagai contoh untuk file konfigurasi ID Server 101 adalah journal.usm.ac.id.conf, untuk ID Server 102 adalah lab.ftik.usm.ac.id.conf dan seterusnya. Adapun isi file konfigurasi pada setiap file tersebut berisi pemetaan IP Private kepada subdomain yang telah ditentukan. Sebagai contoh isi file journal.usm.ac.id.conf pada Gambar 2, yaitu apabila ada permintaan melalui port 80 (web) untuk subdomain journal.usm.ac.id maka diarahkan ke alamat 192.168.135.101.

Seperti yang telah disebutkan sebelumnya, bahwa setiap virtual server akan memiliki file konfigurasi sendiri, maka file tersebut dapat dijadikan acuan pemetaan terhadap permintaan yang masuk (incoming request). Sehingga apabila ada akses dari pengunjung ke subdomain yang tidak tersedia di daftar maka secara otomatis Nginx mengabaikan permintaan tersebut dan pengunjung akan diarahkan ke halaman website Universitas Semarang (http://usm.ac.id).

Selanjutnya untuk keperluan manajemen setiap virtual server, dibutuhkan akses ke server menggunakan layanan $\mathrm{SSH}$. Pada konfigurasi terdahulu, setiap sysadmin cukup melakukan remote akses melalui IP Public menuju port 22 (SSH) untuk dapat melakukan manajemen server, namun karena semua virtual server sekarang telah menggunakan IP Public yang sama, maka sysadmin tidak memungkinkan menggunakan port 22 untuk melakukan remote akses server yang dituju. Maka dari itu peneliti melakukan konfigurasi Port Forwarding terhadap setiap virtual server. 


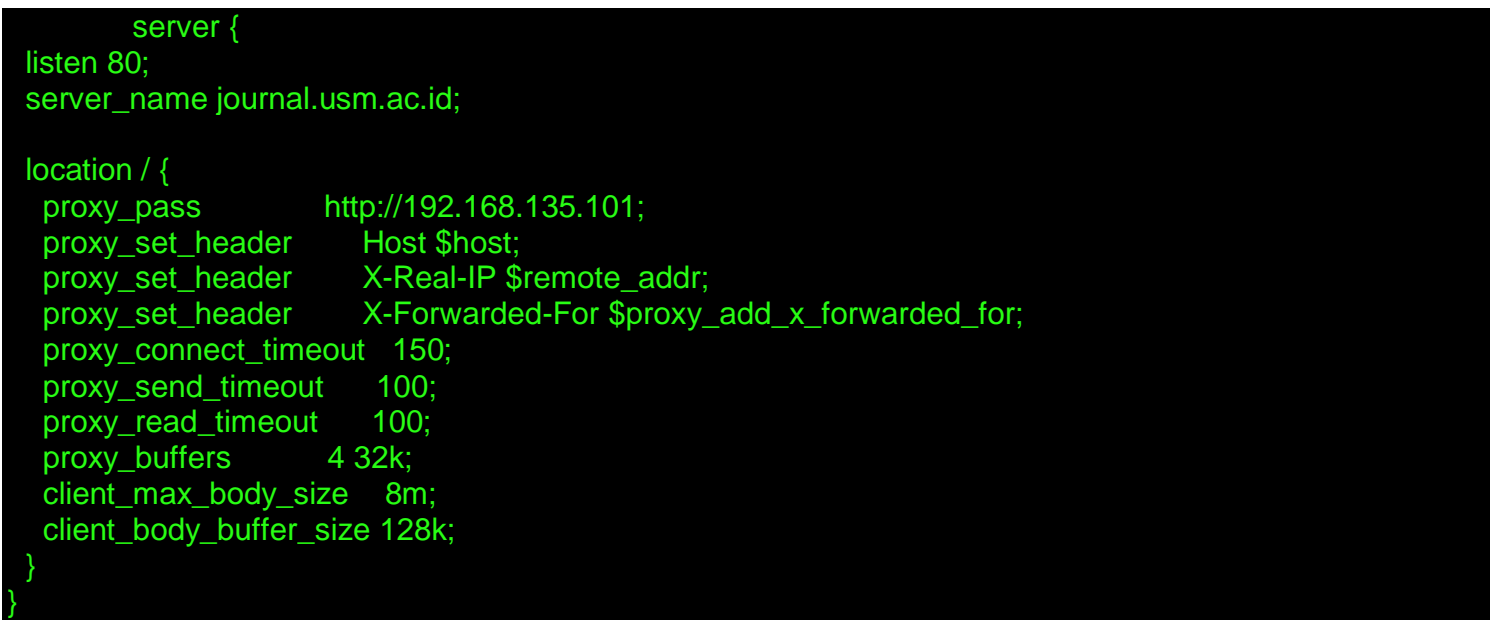

Gambar 2. Konfigurasi Reverse Proxy

Peneliti melakukan konfigurasi Port Forwarding menggunakan aplikasi IPTables yang tersedia pada cloud server. Pemetaan yang dilakukan dengan membuatkan port spesifik yang kemudian diarahkan kepada virtual server yang dituju, adapun daftarnya terlihat pada Tabel 3.

Tabel 3. Daftar Port Forwarding

\begin{tabular}{crc}
\hline ID Server & IP Address & Port Forwarding \\
\hline 101 & 192.168 .135 .101 & 22101 \\
\hline 102 & 192.168 .135 .102 & 22102 \\
\hline 103 & 192.168 .135 .103 & 22103 \\
\hline 104 & 192.168 .135 .104 & 22104 \\
\hline 105 & 192.168 .135 .105 & 22105 \\
\hline
\end{tabular}

Selanjutnya adalah mengonfigurasi IPTables pada cloud server dengan membuat file letc/iptables.rules seperti terlihat pada Gambar 3 yang membuat rule PREROUTING untuk menerima akses dari ethernet fisik server (vmbr0) dengan metode TCP ke port yang telah ditentukan (221101 - 22105) untuk diarahkan menggunakan NAT ke alamat IP virtual server. Hasil dari konfigurasi tersebut memungkinkan sysadmin untuk melakukan akses SSH ke virtual server menggunakan port yang telah ditentukan.

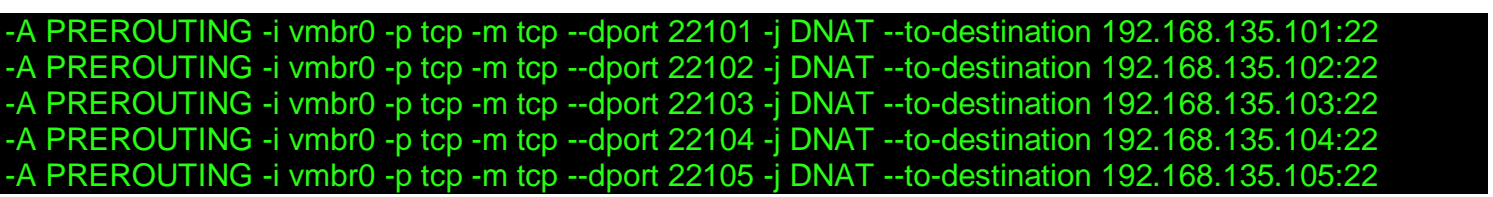
Gambar 3. Konfigurasi Port Forwarding

\subsection{Tahap Operate}

Pada tahap operate, konfigurasi yang telah dilakukan pada tahap Implementasi sudah dapat diuji. Adapun pengujian yang dilakukan dengan mengakses alamat URL subdomain melalui Internet untuk menampilkan halaman website. Karena perubahan konfigurasi sebatas pada pemetaan IP Address dan berada di sisi administrasi jaringan, maka pengunjung sebetulnya tidak merasakan perbedaan saat mengakses website yang dituju.

Pada Gambar 4 terlihat bahwa peneliti dapat mengakses url http://journal.usm.ac.id melalui jaringan Internet menggunakan ISP Smartfren yang terpisah dengan jaringan intranet USM. Hal ini menunjukkan bahwa konfigurasi Reverse Proxy sudah berjalan dengan baik karena Peneliti dapat mengakses website yang berjalan menggunakan IP Private, namun dapat diakses dari Internet menggunakan alamat subdomain.

Selanjutnya untuk pengujian Port Forwarding ke layanan SSH pada setiap server dengan melakukan remote akses dengan menggunakan port yang telah ditentukan. Adapun terlihat Gambar 5 menunjukkan bahwa peneliti dapat mengakses server dengan mengakses host cloud.usm.ac.id dengan port 22101. 


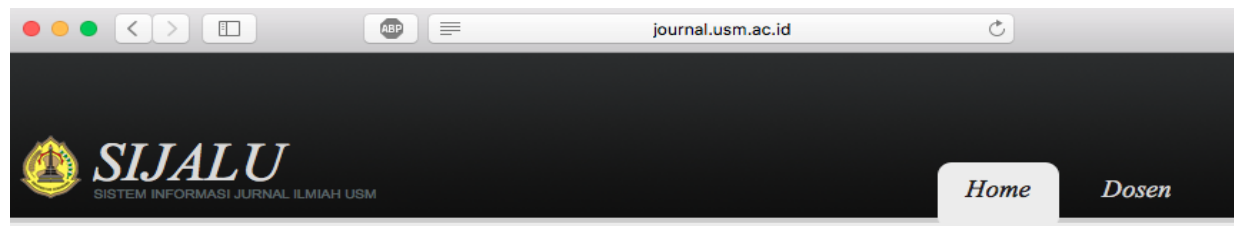

\section{Publikasi Terbaru}

1. Analisa Honeycomb untuk Mendapatkan Balok Paling Ekonomis Berdasarkan Tegangan dan Deformas dengan SAP 2000 Versi 14

Penulis : Ngudi Hari Crista , Bambang Purnijanto, Mukti Wiwoho | Tanggal 17 November 2016

2. TOTAL PROBIOTIK DAN SIFAT KIMIAWI FROZEN YOGHURTPADA PENYIMPANAN BEKU

Penulls : A. Nani Cahyanti, Adi Sampurno | Tanggal 02 November 2016

3. PENGARUH PENAMBAHAN BERBAGAI KONSENTRASI TEPUNG LABU KUNING (Cucurbita moschata

DUrCh) SEBAGAI BAHAN FORTIFIKASI ROTI TAWAR

Penulis : Lydia Ninan Lestario, Putri Malithasari, Susanti Pudj Hastuti I Tanggal 02 November 2016
Minggu, 27 November 2016

藏 Pencarian Jurne

Gambar 4. Tampilan salah satu website di Virtual Server USM

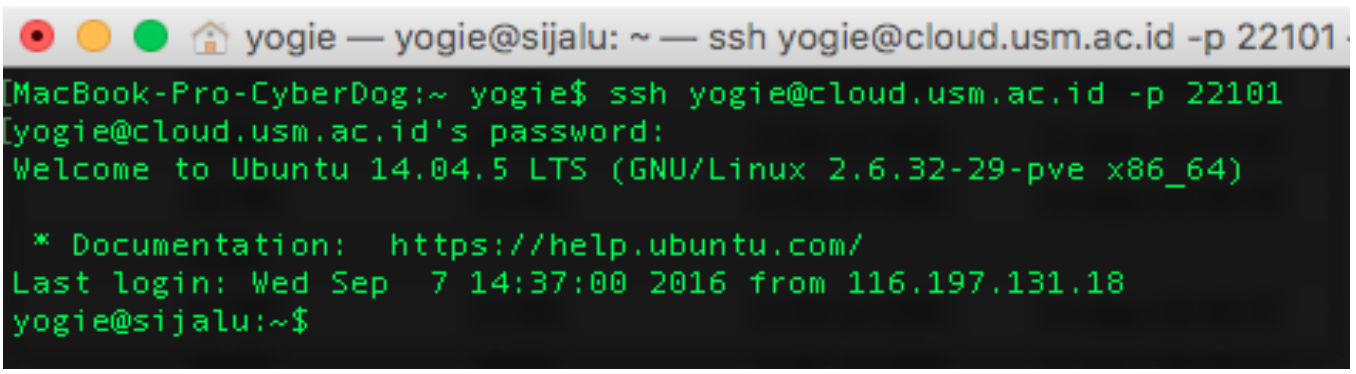

Gambar 5. Remote Akses menggunakan Port Forwarding

\subsection{Tahap Optimize}

Tahap optimize merupakan tahap terakhir pada bagian implementasi. Pada tahap ini, peneliti melakukan monitoring terhadap server Reverse Proxy (ID 100) di alamat 192.168.135.100, dan mendapatkan bahwa memory usage pada server tersebut mencapai $30 \%$ dari jumlah RAM yang diberikan yaitu 512 MB. Maka Peneliti memutuskan menambah jumlah RAM menjadi $1 \mathrm{~GB}$ dan menambah core processor menjadi 2 core seperti pada Gambar 6. Hasilnya saat ini server ID 100 memiliki cukup resource untuk melayani virtual server yang lain (Gambar 7).

Container 100 ('nginx-server-usm.ac-id' )
\begin{tabular}{|c|c||}
\hline Summary & Resources Network \\
\hline Edit
\end{tabular}

$\begin{array}{ll}\text { Processors } & 2 \\ \text { Memory } & 1.00 G B \\ \text { Swap } & 1.00 G B \\ \text { Disk size } & 5.00 G B\end{array}$

Gambar 6. Spesifikasi Server Reverse Proxy

\begin{tabular}{|l|l|l|l|}
\hline Description & Disk usage & Memory usage & CPU usage \\
\hline 100 (nginx-server.usm.ac.id) & $18.8 \%$ & $12.8 \%$ & $0.0 \%$ of 2 CPUs \\
\hline
\end{tabular}

Gambar 7. Status Resource Server Reverse Proxy

\section{Hasil}

Port Forwarding dan Reverse Proxy merupakan fitur standar yang telah ada sebelumnya di semua router. Fitur ini dapat berlaku pada virtual router di jaringan cloud computing. Metode pengembangan PPDIOO (Prepare, Plan, Design, Implement, Operate, and 
Optimize) (Wilkins, 2011) merupakan metode yang tepat untuk memulai pengembangan jaringan komputer. Penggunaan Port Forwarding dan Reverse Proxy dapat mengurangi kebutuhan IP Public, karena cukup menggunakan 1 IP Public kemudian setiap virtual server diberikan IP Private.

Adapun untuk penelitian selanjutnya, dapat difokuskan pada adanya monitoring terhadap traffic paket data yang melewati router supaya dapat dipantau performanya. Kemudian penelitian lebih lanjut mengenai konfigurasi spesifikasi server yang optimal dan terukur terhadap kondisi suatu jaringan cloud. Serta penelitian lebih lanjut untuk membuat pemetaan menjadi lebih dinamis/otomatis karena penelitian ini masih menggunakan metode manual saat membuat file dan membuat rules IPTables.

\section{Referensi}

[1] B. A. N. Cenka, Z. A. Hasibuan, and H. Suhartanto. "The Architecture of Cloud Computing for Educational in Indonesia." Seminar Nasional Aplikasi Teknologi Informasi (SNATI), 2012.

[2] S. Zhang, S. Zhang, X. Chen, and X. Huo. "Cloud computing research and development tren." in Future Networks, 2010. ICFN'10. Second International Conference on, (2010): 9397.

[3] M. S. Suprayogi and A. Ashari. "Implementasi cloud computing menggunakan model adopsi roadmap for cloud computing adoption (ROCCA) pada institusi pendidikan (Studi kasus Universitas Semarang)." M.Cs Master Thesis, IImu Komputer, Universitas Gadjah Mada, Yogyakarta, 2014.

[4] A. Hamzah and I. L. E. Nugroho. "Studi Kasus Penerapan Roadmap for Cloud Computing Adoption (ROCCA) pada Usaha Mikro Kecil dan Menengah." Master Thesis, Universitas Gadjah Mada, 2012.

[5] A. Fardani and K. Surendro. "Strategi Adopsi Teknologi Informasi Berbasis Cloud Computing Untuk Usaha Kecil dan Menengah di Indonesia." Seminar Nasional Aplikasi Teknologi Informasi (SNATI 2011), 2011.

[6] R. R. Nimoko and I. L. E. Nugroho. "Kerangka Pemanfaatan Cloud Computing di Pemerintah Daerah." Master Thesis, Universitas Gadjah Mada, 2012.

[7] J. Postel. "DOD standard internet protocol." 1980.

[8] A. Senong. (2015). Pengguna Internet di Indonesia 73 juta. Available: http://www.antaranews.com/berita/484406/pengguna-internet-di-indonesia-73-juta

[9] R. M. Hinden and B. Haberman. "Unique local IPv6 unicast addresses." 2005.

[10] G. J. d. Groot, Y. Rekhter, D. Karrenberg, and E. Lear. "Address Allocation for Private Internets." 1996.

[11] E. Setijadi, A. Affandi, and S. Sirajuddin. "Rancang Bangun Server Learning Management System Menggunakan Load Balancer dan Reverse Proxy." Jurnal Teknik ITS, pp. A50A52, 2012.

[12] L. Chu-Hsing, L. Jung-Chun, and L. Chih-Chieh. "Detection Method Based on Reverse Proxy against Web Flooding Attacks." in Intelligent Systems Design and Applications, 2008. ISDA '08. Eighth International Conference on, (2008); 281-284.

[13] S. Wilkins. (2011, 23 April). Cisco's PPDIOO Network Cycle. Available: http://www.ciscopress.com/articles/article.asp? $p=1697888$

[14] R. R. Nimoko. "Kerangka Pemanfaatan Cloud computing di Pemerintah Daerah." Masters Thesis, Universitas Gadjah Mada, Yogyakarta, 2012.

[15] H. Li, J. Sedayao, J. Hahn-Steichen, E. Jimison, C. Spence, and S. Chahal. (2009, Developing an Enterprise Cloud computing Strategy. Available: http://www.intel.com/content/www/us/en/cloud-computing/software-as-a-service--saas/intel-it-developing-cloud-computing-strategy-paper.html

[16] Canonical. (2012, 23 September 2013). Public or Private? Cloud Model Checklist. Available: http://insights.ubuntu.com/checklist/cloud-model-checklist/ 